\title{
Treatment of epilepsy in people with multiple handicap
}

\author{
H Foley
}

Eight years ago, the writer visited a home for severely handicapped children, many of whom were epileptic. As it was school holidays, they were all in the hall of an old manor house used as a children's home. In an hour six of the $\mathbf{4 0}$ children had a fit, and six slept on, unrouseable. The experience was memorable.

Since then 51 very severely handicapped epileptic children age between 2 and 16 have been managed personally for at least two years. It has been surprising to see how the treatment pattern has changed over the years, and pleasant to see how few children are now having frequent fits, or are heavily sedated. These children are used as illustrations of the principles involved.

Multiply handicapped people are well known to have epilepsy that is difficult to treat, ${ }^{1}$ especially severely brain damaged children, children with onset of fits in the first year of life, or children who have had infantile spasms or Lennox-Gastaut myoclonic fits. ${ }^{2} 3$ All the children described fall into at least one of these categories. Previous papers on epilepsy in people with multiple handicaps have been about adults. ${ }^{4-6}$ Controlling fits in 'normal' children with one drug can be surprisingly difficult, ${ }^{7}$ and in those with brain damage, it is likely to be even more difficult. However, it is still better to treat with one drug rather than a cocktail. ${ }^{8}$

\section{Patients}

The classification of patients by cause is shown in table 1 . There were 22 boys and 29 girls; 20 were first seen under the age of 5,15 between 5 and 10 , and 16 between 10 and 16. Twenty seven children lived in the manor house, 17 miles from the district general hospital, and 24 lived at home with parents or foster parents.

Twenty seven children had the combination of severe mental handicap, severe cerebral palsy, and severe visual difficulties in addition to epilepsy. Forty five children fell into the

Table 1 Classification of patients by cause of condition $(n=51)$ St Luke's Hospital,
Guildford

Correspondence to: Dr H Foley, Children's Unit, St Luke's Hospital, Guildford, educational classification of severe learning difficulty and 30 were wheelchair bound. Other handicaps included autism, severe deafness, and hydrocephalus. Thirteen children had had infantile spasms, three of the children had tuberous sclerosis, and one had Batten's disease. Seven died during the period of the study.

Several children moved in and out of the area, died, or grew too old for the study. In these cases they are described under the heading 'outcome' as they were on their last visit.

Forty four children arrived with epilepsy already under treatment, which made assessment more difficult. Of these 19 were on more than one drug; two children were on three drugs concurrently. One child with photosensitive epilepsy was provided with dark glasses in sunlight, which were effective. One child with Rett's syndrome was off treatment because her mother thought she was safer on goats' milk (local folklore). The child had no choice. Treatment was begun in seven children.

\section{Types of fit}

Each child's fits were witnessed and identified as fits by at least two experienced observers before treatment was begun.

Classification of the type of fit was difficult. The 51 children had many different types of epilepsy. Fits were counted mainly by parents and care staff, occasionally by nurses, teachers, and doctors. Care staff classified fits as either grand mal or petit mal, and had to be questioned closely about the details of the minor attacks. Fits were classified as recommended by Patten (J Patten, personal communication). This classification was based on his experience with handicapped adults, and used four main groupings, which correlate well with the usual responses of the epilepsies to treatment. These were: classical petit mal (one child), complex partial seizures (26 children), fits involving myoclonus, including akinetic falls ( 10 children), and generalised seizures involving loss of consciousness (43 children). Several children had more than one kind of fit. This simple scheme worked well in practice, so that there was no difficulty in identifying individual types of fit on clinical grounds. Aicardi used a similar classification ( $\mathrm{J}$ Aicardi, paper given at the Fourth International Symposium on valproate and epilepsy, Jersey, 1989). His grouping was 
grand mal epilepsy, partial epilepsy due to brain damage, myoclonic epilepsy (subdivided into severe and benign), febrile convulsions (not discussed here), and West's syndrome (not applicable in this age group).

\section{General management}

The children seemed to respond to a regular life style. They were noted to have more fits on holiday or after a change of home or care staff. In contradiction to the views of O'Donohoe, ${ }^{9}$ three children appeared to have more fits when severely constipated. This is a difficult problem with such immobile children, but a high fibre diet, monitoring of fluid intake, and regular lactulose was helpful. One child appeared to respond to a ketogenic diet but the fits did not recur for some time after when this was subsequently stopped. These children have few things to look forward to each day, so it seems a pity to interfere with their meals on the scale necessitated by a ketogenic diet.

Parents and care staff were instructed to give rectal diazepam if any fit lasted more than five minutes. Stesolid (CP Pharmaceuticals) proved most suitable. Parents needed reassurance that their child was extremely unlikely to die in a fit.

\section{Drug treatment}

The very ambitious initial target was to reduce fits to two a year while keeping the children awake, content, and able to learn, if possible using no more than one drug in each case. This target had to be reduced to exclude short absence seizures of any kind, and attempts were made to minimise these.

It was necessary to discuss changes in medication in detail with parents and care staff. Care staff are more used to seeing patients with fits. Parents are often afraid of 'drugs', and may not give medication in which they do not believe.

The known side effects of the drugs were incorporated in the outpatient letter of which parents automatically received a copy. The risk of fits had to be balanced against side effects, especially drowsiness.

When first seen 11 children were having more than one fit a week but eight had to be woken up to eat. A frequent reason that the children were on so many drugs and so oversedated was that drugs had often in the past been increased to cover an exacerbation of fits and never decreased again. The facts that fits come in clusters, which may be followed by long quiescent periods, had not been recognised.

When children arrived on treatment their current regime was continued while fit activity and drug concentrations were monitored. Investigations were only done when clinically essential. Drug charts were reviewed each month and patients seen according to clinical need.

If fits were not controlled, the most favoured drug was increased to its maximum. If this were proved ineffective, another drug was introduced or increased, and the first drug reduced. When the child was stable, the least favoured drug was reduced very slowly, an adjustment being made every two months or so. When this had finally been withdrawn, any other ineffective drugs were gradually withdrawn in turn until the child was on one drug. When the child had been fit free for two years, the last drug was withdrawn extremely slowly over at least four months. As far as possible treatment was kept well below the maximum recommended level, and sometimes very small doses made a great difference to the number of fits. The treatment given is shown in table 2 .

At first the drugs with least side effects were used (the type of epilepsy being ignored) so that carbamazepine was the first line drug because of the anxiety about sodium valproate jaundice. This proved an ineffective way of controlling many fits, however, so that eventually carbamazepine was still used for generalised seizures as first choice, but sodium valproate was preferred for all seizures involving myoclonus and for complex partial seizures.

The effects of reduction of drugs were often first noted by the teachers, who inquired why the child was 'brighter'. The sister in charge in the children's home approved of the simplification of the drug round, and the care staff commented on the improvement in the children's alertness and noted that they were making more sounds. However two children were admitted to hospital in status epilepticus.

Drug doses were those suggested by Addy. ${ }^{10}$ The sister in the children's home preferred tablets which she crushed, but parents generally preferred sugar free liquids. In general drugs were given twice daily. Sometimes a midday dose of sodium valproate was given, and sometimes a late night dose of any drug reduced nocturnal and early morning fits, but this usually meant waking the children and was particularly unpopular where children lived at home.

Blood concentrations were used to monitor phenytoin, phenobarbitone, and carbamazepine.

\section{Outcome}

At the end of the treatment period nine (18\%) had come off drugs and were fit free. Two children had been off drugs for about a year but fits recurred, 19 had no fits on treatment in the past six months, 12 were having fits less often than once a month, and three about once a week, but three children on drugs continued to have several fits a week. Of these, one had several akinetic falls each week so that he had to wear a protective helmet. Increasing any treatment made him silent and miserable. One child had tuberous sclerosis and one, with a cerebral malformation, became drowsy on all agents tried. Not surprisingly, the child on goats' milk

Table 2 Treatment according to seizure type*

\begin{tabular}{llll}
\hline Seizures type & $\begin{array}{l}\text { Off all } \\
\text { drugs }\end{array}$ & $\begin{array}{l}\text { Taking one } \\
\text { drug only }\end{array}$ & $\begin{array}{l}\text { Taking more } \\
\text { than one drug }\end{array}$ \\
\hline Petit mal & 1 & - & -1 \\
Complex partial & 2 & 13 & 11 \\
Involves myoclonus & - & 3 & 7 \\
Generalised & 8 & 20 & 15 \\
\hline
\end{tabular}

*Twenty three children had more than one type of fit. 
(at parent's insistence) continued to have complex partial seizures. Table 3 shows the outcome of the children, and table 4 the number of drugs given, before and after rationalisation of drug treatment.

The fits of 17 children were controlled on sodium valproate alone, four on carbamazepine alone, two on phenytoin, and one on clobazam.

Thirteen children still needed two drugs. Four were on carbamazepine and sodium valproate, two (with myoclonus) on carbamezapine and methsuximide, three (with generalised fits and myoclonus) on sodium valproate and primidone, two (with generalised fits and myoclonus) on sodium valproate and clonazepam, one on carbamazepine and phenobarbitone, and one on sodium valproate and phenytoin. One child still needed three drugs.

\section{Cost}

The daily cost of the medication was approximately the same at the end of the treatment modifications. Fewer more expensive drugs had been substituted for less expensive but ineffective agents. Initially 71 individual drug doses were given out each day but by the end of the treatment period only 57 were needed.

\section{Side effects}

The side effects of the modified regimes were surprisingly few. Thirteen children had been very drowsy on arrival, especially those on multiple treatment. One child developed erythema nodosum on phenobarbitone, two were very miserable on carbamazepine, one stopped eating on primidone. One was overactive and two miserable on diazepam (this had been used previously to reduce muscle tone). A child with tuberous sclerosis became aggressive and sleepless on everything except sodium valproate and carbamazepine. One child developed abnormal liver function tests but these returned to normal when the sodium valproate was withdrawn. No rashes and no alopecia were seen and no blood dyscrasias detected.

In this group there was no clinical problem with sodium valproate, although weight gain may be a problem with this drug. Of the 18 children still on sodium valproate at the end of the

Table 3 Outcome of children before and after rationalisation of drug treatment

\begin{tabular}{lllllll}
\hline & \multicolumn{3}{l}{ On drug treatment } & & $\begin{array}{l}\text { No drugs: } \\
\text { no fits }\end{array}$ & $\begin{array}{l}\text { Goats' milk: } \\
\text { frequent fits }\end{array}$ \\
\cline { 2 - 6 } & Frequent fits & Few fits & No fits & & \\
\hline Before & 22 & 20 & 7 & 1 & 1 \\
After & 9 & 31 & 0 & 10 & 1 \\
\hline
\end{tabular}

Few fits means less than one fit a month but still on drugs.

Table 4 Number of drugs given before and after rationalisation of drug treatment

\begin{tabular}{|c|c|c|c|c|}
\hline & $\begin{array}{l}\text { No } \\
\text { drugs }\end{array}$ & $\begin{array}{l}\text { One } \\
\text { drug } \\
\text { only }\end{array}$ & $\begin{array}{l}\text { Two } \\
\text { drugs }\end{array}$ & $\begin{array}{l}\text { Three } \\
\text { drugs }\end{array}$ \\
\hline $\begin{array}{l}\text { Before } \\
\text { After }\end{array}$ & 21 & $\begin{array}{l}27 \\
24\end{array}$ & $\begin{array}{l}19 \\
15\end{array}$ & $\begin{array}{l}3 \\
1\end{array}$ \\
\hline
\end{tabular}

series, there were two ambulant children whose height and weight were above the 90th centile (probably familial). One child was on the 75th for both height and weight, and three on the 50th for height and weight; two were below the 25 th, three below the 10th, and seven below the 3rd for weight. These figures emphasise that poor weight gain is a serious problem in nonambulant spastic children, so much so that some have needed gastrostomies to increase their energy intake. ${ }^{11}$

Phenytoin proved to be a difficult drug to use in the multiply handicapped child because many have neurological disabilities similar to the recognised side effects of the drug, and the repeated blood tests were frightening for them, especially if they were blind. One child on phenytoin stopped eating and lost weight. The care staff noted that her tongue was rolling up in her mouth when she tried to chew. A very small (25 $\mathrm{mg}$ ) increase in dosage had pushed her phenytoin into the toxic range and reducing the dose allowed her to eat again. Choreiform movements are a known side effect of phenytoin. ${ }^{9}$ Two children on phenytoin had gingival hyperplasia.

Phenobarbitone and clonazepam both caused sedation and produced behaviour problems. ${ }^{912}$ These, mainly immobile, children showed irritability rather than hyperactivity. Clobazam at night did not sedate during the day.

As so many children had more than one type of fit, it was not easy to say which fit type responded to which drug. Sodium valproate and carbamazepine were both effective in some children with generalised and/or complex partial seizures. Myoclonic seizures responded least but sodium valproate proved to be most effective for this seizure type.

The drugs in principal use were sodium valproate and carbamazepine, but phenytoin, methsuximide, phenobarbitone, clonazepam, and clobazam were used occasionally. Grand mal and complex partial seizures both responded in part to either sodium valproate or carbamazepine (this differs from the conclusions of Aicardi who regards sodium valproate as a second line drug here ${ }^{1}$ ) but for a few children the older, more sedative anticonvulsants phenytoin and primidone were needed. Carbamazepine was not effective in myoclonus.

One child with gelastic epilepsy responded to carbamazepine. Exaggerated startle responses were intractable but it was possible to prevent their progression to grand mal as had occurred in two children. Previous infantile spasms proved not necessarily a bad prognostic sign; six out of 13 children who had had them had one fit a year during the observation period.

Control of epilepsy in the children in care proved as difficult as in those living at home.

Children on one drug only at the end of the series are shown in table 5.

\section{Addendum}

Since these figures were compiled, one year ago, one child in the 'few fits' group has died, and two children have moved from 'frequent fits' to few fits. The child who came off the ketogenic 
Table 5 Patients on one drug only in each seizure group at end of series

\begin{tabular}{llllr}
\hline Fit type & Carbamazepine & Clobazam & Phenytoin & Sodium valproate \\
\hline Complex partial & 3 & - & 1 & 8 \\
Involves myoclonus & $\mathbf{3}$ & 1 & $\frac{1}{2}$ & 13 \\
Generalised seizures & & & & 13 \\
\hline
\end{tabular}

diet has begun to have very frequent fits and is taking acetozolamide. The child who came off primidone because of anorexia and continued to have one or two fits a week is settling down on sodium valproate and phenytoin. One child stabilised previously on sodium valproate, with complex partial seizures consisting of staring and mouth twitching, has started to have generalised fits and aphasic episodes and is responding to phenytoin in addition. One child with hydrocephalus, in the few fits group, on carbamazepine and methsuximide deteriorated and was found to have a posterior fossa tumour. A child with Rett's syndrome had an increasing number of generalised and complex partial seizures on carbamazepine but so far is responding to sodium valproate. These children therefore are continually changing and need regular review. Of the three children with fits almost daily, one had left the children's home. One with severe akinetic falls was changed from carbamazepine and methsuximide to sodium valproate (which had been tried previously unsuccessfully) and is much happier, and only having two to three falls a week. The child with tuberous sclerosis is still having almost daily fits, during which she may vomit.

\section{Conclusions}

It is possible to treat many severely handicapped children with epilepsy so that they have few fits and are not sedated. A total of $54 \%$ of the children in this series were off drugs, or controlled on one drug only without sedation. Four children remained uncontrolled (three on treatment, one on goats' milk at mother's request).

In this group it proved possible to reduce both the number of drugs used and the number of fits. The balance between control and sedation was always difficult, and it seemed more important to keep the children awake, content, and able to learn, rather than entirely fit free. Care staff were experienced with fits and relaxed about permitting brief ones. It was possible to persuade most parents to accept that occasional short fits were preferable to sedation, provided that they had rectal diazepam to hand.

It is important to review children regularly to see if drug reduction is possible, and because the situations change. Increases to cover a series of fits need not become a permanent feature of the regime.

Sodium valproate seems to be the drug of first choice for fits involving myoclonus and for complex partial seizures in severely handicapped children over 3 years old, who have normal liver function tests, and have no suggestion of a biochemical cause for their condition. Carbamazepine is the first choice in generalised seizures with sodium valproate being substituted if carbamazepine fails. Rationalising drug treatment did not increase expenditure.

I should like to thank Dr John Patten, consultant neurologist to the SW and NW Surrey Health Districts, for his kind and expert help with some of my most difficult patients; Dr Frances Howard for her advice in the drafting of the paper; Dr J M Fallowfield and Miss Helen Archer of Sanoffi Labaz for help with tables; Sister MacElhatton; and also my sons Paul and Stephen Foley for help with the computer.
fister MacElhatton; and also

1 Aicardi J. Clinical approach to the management of intractable epilepsy. Dev Med Child Neurol 1988;30:429-40.

2 Brown JK. Valproate toxicity. Dev Med Child Neurol 1988; 30:121-5.

3 Laidlaw J, Richens A, Oxley J. A textbook of epilepsy. Edinburgh: Churchill Livingstone, 1988 .

4 Beghi E, Bollini P, DiMascio R, Cerisola N, Merloni T, Manghi E. Effects of rationalising drug treatment of the patients with epilepsy and mental retardation. Dev $\mathrm{Med}$ Child Neurol 1987;29:363-9.

5 Bennett HS, Dunlop T, Ziring P. Reduction of polypharmacy in an institution for the mentally retarded. Dev Med Child Neurol 1983;25:735-7.

6 Clarke BG, Bledsoe MA, Lewis J, Thomson LL. Monotherapy in institutionalised epileptics. Drug Intell Clin Pharm 1986;20:156.

7 Forsythe WI, Sills MA. One drug for childhood grand mal.

8 Wev Med Child Neurol 1984:26:742-8. monotherapy. Epilepsia 1987;28(suppl 2):S1-7.

9 O'Donohoe NV. Epilepsies of childhood. Dublin: Butterworths, 1985 .

10 Addy DP. Childhood epilepsy. Br Med $\mathcal{F}$ 1978;ii:811-2.

11 Patrick J, Boland M, Stoski D, Murray GE. Rapid correction of wasting in children with cerebral palsy. Dev Med Child Neurol 1986;28:734-9.

12 Abu-Arefeh IA, Wallace SJ. Unwanted effects of antiepileptic drugs. Dev Med Child Neurol 1988;30:117-21. 